\title{
Sobre literatura lésbica e ocupação de espaços
}

\author{
On Lesbian Literature and the Occupation of Spaces
}

Sobre literatura lesbiana y ocupación de espacios

Natalia Borges Polesso

\section{Resumo}

Este ensaio busca delinear uma reflexão acerca da ideia de literatura lésbica, atrelada ao conceito de geografias lésbicas (Browne e Ferreira, 2015). Para tanto serão discutidas as ideias de lesbianidades plurais em perspectivas que consideram performances de gênero, interseccionalidade e decolonialidade. O espaço é fundamental para a perspectiva que essa discussão pretende tomar, pois é no espaço que as relações identitárias, sociais e de gênero acontecem, entram em conflito e expõem suas vontades de dominação e suas incompletudes. Com a ocupação dos espaços, sejam geográficos, epistêmicos, teóricos ou literários, por essas lesbianidades, é possível que novas propostas éticas e estéticas entrem em jogo. Considerando lésbica - e mais tarde lésbica - como um adjetivo, desejamos desvelar quais novas leituras críticas podem ser empreendidas no campo literário.

Palavras-chave: literatura lésbica, relações de poder, espaços.

\begin{abstract}
This essay aims to outline a reflection on the idea of lesbian literature, connected to the concept of lesbian geographies (BROWNE et FERREIRA, 2015). Therefore, the ideas of plural lesbian identities will be discussed in perspectives that consider performances of gender, intersectionality and decoloniality. Space is fundamental to the perspective that this discussion intends to take, as it is in space that identity, social and gender relations take place, come into conflict and expose their dispositions towards domination and their incompleteness. The occupation of spaces, whether geographical, epistemic, theoretical or literary, by these lesbian existences, makes possible that new ethical and aesthetic proposals come into play. Considering lesbian - and later lesbian - as an adjective, we wish to reveal what new critical readings can be undertaken in the literary field.
\end{abstract}

Keywords: lesbian literature, power relations, spaces.

\begin{abstract}
Resumen
Este ensayo busca esbozar una reflexión sobre la idea de la literatura lésbica, vinculada al concepto de geografías lésbicas (BROWNE et FERREIRA, 2015). Con este fin, las ideas de las lesbianas plurales se discutirán en perspectivas que consideren los desempeños de género, interseccionalidad y descolonialidad. El espacio es fundamental para la perspectiva que esta discusión pretende tomar, ya que es en el espacio donde tienen lugar las relaciones de identidad, sociales y de género, entran en conflicto y exponen su voluntad de dominar y su incompletitud. Con la ocupación de espacios, ya sean geográficos, epistémicos, teóricos o literarios, para estas lesbianas, es posible que entren en juego nuevas propuestas éticas y estéticas. Considerando lésbica, y después lesbiana, como un adjetivo, deseamos revelar qué nuevas lecturas críticas pueden llevarse a cabo en el campo literario.
\end{abstract}

Palabras-clave: literatura lésbica, relaciones de poder, espacios.

Piso essa geografia como quem deseja dominar o espaço. Um pé firme sobre o chão e depois o outro, movimento diligente. E tropeço. Penso que agora deveria estar em pé, no alto de uma montanha, como na pintura do caminhante à espera da dissipação do mar de névoa, mas à distância não posso observar as minúcias da paisagem nem sua humanidade. Também, não se pode cartografar impunemente. Ou se escala a montanha e dali se observa o todo ou se vai ao rés do chão para se observar o mínimo, a gruta, a curva, o capim molhado, os edifícios, por trás

\footnotetext{
"Universidade de Caxias do Sul, Caxias do Sul, RS, Brasil. (Dorcid.org/0000-0002-7618-1288. E-mail: nbpoless@ gmail.com
} 
de suas vidraças, as casas e as gentes. Desejar apenas o olhar vertical sobre o mapa é privar-se da viagem, do percurso, da experiência, do que pode ser o horizonte, e o que vem depois. Mas quem adentra o espaço tampouco o domina integralmente. Toda dominação é falsa. Ilegítima. No sentido de que nunca será completa. Há escolhas. Há sempre brechas.

Portanto, é impossível não me colocar no mundo de duas formas para esta discussão sobre lesbianidades, literatura e espaços. Preciso estabelecer pontos de vistas. Preciso ter a noção de que os lugares em que me coloco não são estáticos e afetam a minha visão, privilegiando algo em detrimento de outro algo. Mesmo assim preciso pisar a geografia e tropeçá-la. Preciso compreender o que o mapa diz.

É fácil olhar um mapa pronto. Observar os pontos marcados. Fazer uma lista de nomes e lugares. O complexo é relacioná-los. Extrair deles algo que não seja o óbvio. Não quero reproduzir espaços que não são mais do que a imagem ultrarrealista de onde agora tenho o corpo inteiro fincado. A imagem que me dá impressão de saber tudo, submergir no ambiente sem a névoa, com todos os detalhes, suas complexidades, espaço extático. Se me levanto, há horizonte, há expectativas e há devires. O devir é um dos aspectos mais importantes da estrutura do horizonte e a fenomenologia a utiliza para o entendimento da experiência do sensível, que Michel Collot, por sua vez, engloba na sua definição de pensée-paysage, dizendo que "uma coisa não é jamais percebida senão na sua relação com as outras no interior de um campo, de um horizonte externo" (Collot, 2011, p. 25, tradução nossa). Assim, do mesmo modo que deve se levar em conta esse horizonte, sua face oculta será sempre uma perspectiva subjetiva, um ato de pensamento, em que se pode criar uma ligação com a realidade referencial e um ponto de vista particular sobre o mundo. Uma expectativa ou sua leitura. O mapa é importante porque estabelece uma noção do que, naquele momento, se propõe a ser completo. Já o percurso importa, porque faz pensar a paisagem que se suspende e se desintegra no olhar do outro. De modo que este é um percurso errante, que procura discutir algumas noções-chave que se colocam como passagens ou como bloqueios, como avenidas amplas e como trilhas fechadas, nessa vasta discussão sobre geografias e literaturas lésbicas (ou lésbicas).

Então, quais são meus pontos de observação? Sou uma mulher branca, cis, lésbica, brasileira, latino-americana, de esquerda, sou uma mulher ansiosa, uma mulher fora de algum eixo, dentro de algum eixo, sou queer, não tenho útero, sou uma escritora e pesquisadora, nasci no interior do Rio Grande do Sul, no seio de uma família simples, de classe trabalhadora. Sou a primeira doutora da família. Nesse momento, sou uma mulher lésbica, fazendo um estágio pósdoutoral em uma universidade privada com uma bolsa da Capes. Sou uma mulher que não respira tranquila no Brasil de 2020, porque compreende o seu desmonte cultural, educacional, político, social. Sou uma mulher que compreende seus privilégios dentro das estruturas sociais, sou uma mulher que tenta se engajar nas lutas antirracistas, anticapitalistas, anti-homofobia, e que percebe que tudo isso é um exercício constante de reflexões e ações, um aprendizado. Nesse momento, é importante dizer que vivemos num simulacro de democracia, minada por ideologias políticas que se ligam a movimentos racistas, fascistas, genocidas, de extrema direita. Os espaços estão em tensão. Os espaços LGBTQ+ estão em tensão. Nossa existência individual está ameaçada e nossa existência coletiva se torna alvo. As fragilidades e as ignorâncias sociais estão expostas. Para mais ou para menos. Também nossas forças se revelam, para mais ou para menos. As violências e opressões são exercidas sobre os corpos e a gravidade social delas vai depender do corpo e do espaço que este ocupa.

Estabelecer identidades não é algo simples quando nos espaços as estruturas da opressão e do privilégio são móveis. Os cruzamentos culturais, econômicos, raciais, de classe, nos interpelam a todo o momento, por todos os lados, fazendo com que tudo o que tentemos construir seja sempre muito instável; ainda assim, é preciso estar consciente do/no mundo. Glória Anzaldúa diz algo importante sobre o rotular a si mesma e que talvez seja importante para pensarmos algo por aqui:

rotular a mim mesma é para que a chicana e lésbica e todas as outras pessoas em mim não sejam apagadas, omitidas ou assassinadas. Nomear é como eu faço minha presença 
conhecida, como eu me afirmo quem e o que eu sou e como quero ser conhecida. Nomear a mim mesma é uma tática de sobrevivência (Anzaldúa, 2017, p. 410).

Aí está a razão de minha brevíssima anamnese. Somo-me à decisão da teórica numa autonomeação que, neste ensaio, é principalmente geopolítica. Somo-me à decisão da teórica para dizer que penso em questões de leituras identitárias hegemônicas e não hegemônicas há algum tempo. Por exemplo, penso no significado de ser escritora há muito tempo. Muitas respostas me agradam. Sou escritora porque escrevo, sou escritora porque publico, sou escritora porque posso ser e isso não é simples, sou escritora porque me leem, porque tenho distribuição, sou escritora porque tenho recepção crítica, sou escritora porque dizem que sou escritora e se todas essas respostas deixarem de ser verdade, ainda assim, serei escritora, porque quero exercitar o ofício da escrita. Assim, a questão reside parte em minha atuação no campo e parte em sua legitimação. Agora, o que quer dizer ser lésbica, afinal? Há quanto tempo tenho pensado minha própria sexualidade, minha lesbianidade, minha cisnormatividade, meu sentimento ou pertencimento queer, minha branquitude, meu estar geográfico. Há quanto tempo tenho pensado em como me encaixo e me desencaixo de algumas estruturas? Depende. Para ser honesta, não sei dizer ao certo. Sei que são necessidades do nosso tempo, sei que são urgências. Passei grande parte da minha vida fingindo que minha sexualidade não importava. Passei muito tempo negando desejos e quando eles se concretizaram, passei muito tempo me estranhando, achando-me excêntrica. Até poder me achar parecida com alguém. Depois veio a autoaceitação e tudo ficou mais calmo dentro. Porém, essa aceitação precisa também estar fora de mim, a meu redor, nos outros, na composição social dos espaços, na busca por bem-estar, conforto físico e emocional. Sendo assim, a aceitação não pode estar apenas vinculada a mim; quando eu habito o mundo, ela reside parte em assumir minha identidade, parte em sua legitimação nos campos sociais. Há questões complexas que são estruturais, e isso não quer dizer que sejam abstratas e anônimas, ao contrário, estão profundamente enraizadas nas práticas sociais (coloniais), nas opressões hierárquicas sofridas ou perpetradas do racismo, do machismo, da LGBTQfobia, do classismo, da gordofobia, entre outras e que são reproduzidas diariamente por todos nós. Então, pensar profundamente sobre a dimensão política principalmente da minha lesbianidade, bem como de todos esses atravessamentos interseccionais, como exercício de escrita é algo urgente.

Laura Arnés (2016), considerando o percurso das ficções lésbicas desde o século XIX, afirma que a entrada no século XXI tornou o panorama literário e o panorama social mais complexo.

Com o passar dos anos, a voz ganhou corpo. Os corpos lésbicos foram expandindo-se, eroticamente, até conquistar o corpo do texto, até desarticular ficções amorosas e edipianas, até transfigurar o texto em corpo, em língua e finalmente, em cunilíngua. Assim, no século XXI as ficções lésbicas já têm voz e corpo. Resta-lhes agora deixar-se guiar por seus afetos: apropriar-se do espaço, desenhar paisagens e caminhos (Arnés, 2016, p. 17, tradução nossa).

Desse modo, como pesquisadora e escritora do século XXI, não posso me furtar a discutir esses pontos de vista dentro do campo literário e do campo acadêmico, ou seja, dentro de estruturas, reconhecendo suas tensões, reconhecendo também que este ponto de vista por vezes responde e por vezes não responde às ideias da crítica colonizada, colonizadora, heterocentrada, branca e cisnormativa, reconhecendo que é um ponto de vista divergente das narrativas hegemônicas falogocêntricas, mas que, por vezes, ocupa algum lugar confortável nessas órbitas, a depender dos atravessamentos. Foram os deslocamentos reais que a literatura me proporcionou que me fizeram pensar melhor sobre essas questões de um modo mais abrangente, considerando a produção literária de mulheres LBTQIAP.

O gênero é um aparato e, por ser parte constitutiva das identidades, sua performance é sempre política. Isso faz com que aspectos das sexualidades e das identidades sejam também políticos e, portanto, públicos. Segundo Judith Butler (2004)

O gênero não é exatamente o que alguém "é" nem é precisamente o que alguém "tem". $\mathrm{O}$ gênero é um aparato pelo qual a produção e a normatização do masculino e do feminino acontecem juntamente com as formas intersticiais de hormônios, cromossomos, psique e 
performance que o gênero presume. Presumir que o gênero sempre e exclusivamente significa a matriz do "masculino" e do "feminino" é precisamente perder o ponto crítico de que a produção daquele binário coerente é contingente, que isso vem a custo de algo e que aquelas permutações de gênero que não cabem no binário são tão parte do gênero quanto às instâncias mais normativas. Combinar a definição de gênero com suas expressões normativas é inadvertidamente reconsolidar o poder da norma de restringir a definição de gênero. Gênero é o mecanismo pelo qual as noções de masculino e de feminino são produzidas e naturalizadas, mas gênero pode muito bem ser o aparato pelo qual tais termos são desconstruídos e desnaturalizados (Butler, 2004, p. 42, tradução nossa).

Sendo assim, o gênero leva a operar dentro de certas estruturas discursivas, que também são políticas. Isso significa que, muitas vezes, essas são políticas de exclusão, de dominação, de exploração, de privação, de roubo, de confinamento, de restrição e de controle. Contudo essas opressões se tensionam mais ou menos a depender dos espaços e de outros atravessamentos estruturais da sociedade (racismo, homofobia, transfobia, etarismo, gordofobia, preconceitos com neuroatípicos etc.). Então, para algumas escritas autorais de corpos que exercem práticas ex-cêntricas de desejo não apenas sexual, mas erótico, as políticas lavradas em contratos de heterossexualidade, branquitude, colonialidade e normatividade ficam em desencaixe, suspensas ou em conflito.

No caso de mulheres LBTQIAP, é preciso lembrar-se do que fala Monique Wittig (1992). A autora diz que a divisão dos sujeitos nas categorias homem e mulher e a instituição da heterossexualidade como sistema político e econômico é a prática para a dominação das mulheres na base do pensamento, o que ela denominou como "pensamento straight" ou "pensamento hétero".

Desse modo, as escolhas, em maior parte, não conformativas da literatura que proponho discutir como sendo literatura lésbica desestabilizam as estruturas desse contrato social heterossexual e desse pensamento hétero, e criam uma sombra em seu supostamente "bom" funcionamento e nas bases normativas da sociedade em que vivemos e pela qual nossas performances e comportamentos são constantemente regulados. Pensando em questões de geografia literária e geocrítica (Collot, 2014), há textos que não apenas lírica e narrativamente apresentam esses desencaixes para essas estruturas, mas também em seus meios de produção, distribuição e circulação. Não quero de nenhuma forma homogeneizar essa produção, ao contrário, a mirada geográfica permite problematizar outros eixos. Cabe aqui uma pequena explicação sobre como este ensaio se desdobra de uma pesquisa maior chamada "Geografias lésbicas: literatura e gênero" (Polesso, 2018).

Segundo Laura Arnés (2016), a literatura é um dispositivo político em que se modulam múltiplas distribuições do que afeta nossos mundos sensíveis e onde novas relações aparecem constantemente entre os corpos. Dessa forma, pensar a literatura acoplada ao adjetivo lésbica cria múltiplas possibilidades e recortes para um novo olhar acerca de suas produções e espacialidades. Considerando esses cruzamentos, proponho que as lesbianidades em literatura sejam pensadas via geografia. Abordar a literatura pelo viés da geografia literária e da geocrítica nos desonera de recortes preestabelecidos e nos proporciona pensar outros modos de compreensão das identidades e espacialidades no mundo, que não fundamentalmente ligadas ao tempo histórico, nem a recortes temáticos redutores. Conforme Collot (2014), a geografia literária está interessada: i) no espaço que a literatura produz; ii) na maneira como ela o produz; e iii) nas projeções dessa produção. Se a produção social está irrefutavelmente conectada à produção do espaço, qualquer movimento humano é produção espacial. Seus percursos, trajetos, até a forma como constrói seu pensamento, seja no referente do mundo, seja em suas construções narrativas literárias são produções de sentido espacializadas. Mais especificamente, tratando-se de geografias lésbicas, o livro organizado por Browne e Ferreira e (2015), intitulado Lesbian geographies: gender, place, and power, traz questões mais pontuais e específicas, que dizem respeito a onde e como vivem, trabalham, têm lazer e transitam indivíduos que se identificam como, reivindicam o termo ou podem ser vistos como lésbicas (cis ou trans, bissexuais e/ou mulheres queer); ou, ainda, dizem respeito a como essas pessoas se encontram em determinados 
lugares e também como elas negociam os lugares onde são ou não são bem-vindas, estão sujeitas a abusos e onde se sentem inseguras ou seguras. Ainda conforme Collot (2014), na literatura, a geografia opera em dois níveis: i) em geografia literária, que se ocupa do mapeamento de itens no mundo; e ii) em geocrítica, que se ocupa do mapeamento das referências espaciais ficcionais que os textos carregam. Assim, para esta pesquisa, no campo da geografia literária, temos a localização da autoria no espaço real (mundo) e, para a geocrítica, as potencialidades dos espaços e das espacialidades em termos de criação.

O objetivo deste trabalho nunca foi definir o que seria uma literatura lésbica, ao contrário, o interesse é problematizar esse termo como parâmetro norteador para mapear quando, onde e em que condições autoria e protagonismo ficcional/lírico emergem na literatura (quem são as autoras dessas representações, que tipo de espaços estão construindo, como compreendem seu estar no mundo e como constroem suas personagens) para que se possa chegar a uma discussão mais complexa que envolva aspectos políticos, éticos e estéticos no seio dessa produção.

Por isso também, é precavido e necessário reafirmar que sou uma escritora e pesquisadora cis, lésbica brasileira, branca, latino-americana, relativamente periférica e essa leitura tem implicações. Quando escrevo, escrevo com meu corpo inteiro, de lugares geográficos (não apenas espaciais, mas culturais, políticos, sexuais, econômicos etc.) específicos, com confluências e, ao mesmo tempo, transitórios. Lugares que também são construídos nas tensões e afinidades coletivas, em relação a outras escritas. Isso não quer dizer que a minha escrita vai ser o reflexo exato de quem sou, isso quer dizer que a minha prática criativa será afetada pelo meu estar no mundo nessas condições.

Quando proponho discutir a produção literária específica de mulheres LBTQIAP, o faço com o intuito de dizer que ela se articula a partir desse ponto de vista, que também é instável, mas definitivamente não conformista e não normativo, que é reivindicatório de espaços e está sendo ameaçado constantemente, que é ex-cêntrico nas práticas eróticas e por isso sobremaneira interessante. Penso que as implicações das escritas desses corpos lésbicos espacializados configurem uma literatura lésbica (ou lésbiea), do ponto de vista político e estético. Jamais reduzida ao temático. Jamais gravitando apenas o eixo da sexualidade, descolada do mundo. São pessoas completas a ocupar espaços por vezes hostis. São pessoas completas criando, reivindicando e reinventando espaços de afeto. A rasura do termo lésbica dentro do parêntese vem de uma inquietação teórica que se constrói paulatinamente e tenta propor alguma reflexão sobre o que o termo carrega de complexo em si sem esquecer o que ele apaga por ser um termo eurocêntrico e mormente branco. Há teóricas que trabalham com os termos sapatão, butch, dyke, torta, lesbiana entre outros. Em função do nome do projeto, advindo do conceito cunhado por Browne e Ferreira (2015) (Lesbian geographies), optei por utilizar a palavra lésbica como parâmetro. Compreendendo que universalismos são homogeneizantes e redutores, o uso da rasura traz uma marca gráfica dessa discussão, que deixarei para outro momento, quiçá para um artigo específico. Aqui, penso em lésbica, como pensa Adrienne Rich, como existência e como continuidade.

Existência lésbica sugere tanto o fato da presença histórica de lésbicas quanto da nossa criação contínua do significado dessa mesma existência. Entendo que o termo continuum lésbico possa incluir um conjunto - ao longo da vida de cada mulher e através da história - de experiências de identificação da mulher, não simplesmente o fato de que uma mulher tivesse alguma vez tido ou conscientemente tivesse desejado uma experiência sexual genital com outra mulher. Se nós ampliamos isso a fim de abarcar muito mais formas de intensidade primária entre mulheres, inclusive o compartilhamento de uma vida interior mais rica, um vínculo contra a tirania masculina, o dar e receber de apoio prático e político, [...]. A existência lésbica inclui tanto a ruptura de um tabu quanto a rejeição de um modo compulsório de vida. É também um ataque direto e indireto ao direito masculino de ter acesso às mulheres. Mas é muito mais do que isso, de fato, embora possamos começar a percebê-la como uma forma de exprimir uma recusa ao patriarcado, um ato de resistência (Rich, 1986, p. 35-36).

Nesses espaços de tensão, as identidades fluem mais ou menos. Anzaldúa (2017) afirma que a identidade é uma espécie de rio, que precisa fluir e mudar para continuar em seu processo de ser rio, pois, se estancasse, seria um corpo de água contido. Entender que a compreensão de nós 
mesmos é um exercício constante de rasuras e reescritas que ocorre dentro dos códigos representacionais de que estamos cientes, os quais sabemos mais ou menos articular, é o mesmo que compreender que esse processo se constitui colado nas estruturas ideológicas. Segundo Jagose (2017, p. 489), “[e]ssa noção é importante para qualquer exame mais aprofundado sobre políticas identitárias, porque demonstra como a ideologia não apenas posiciona os indivíduos na sociedade, como também confere a eles seu senso de identidade". Ainda assim, são processos criativos de afirmação e de reivindicação que, por meio da literatura, produzem e atualizam metáforas de existências.

Então, se essas produções criam $\mathrm{f}(\mathrm{r})$ icções que atualizam metáforas e que propõem certa resistência à heterossexualidade, à cis-heteronormatividade, à regulação dos corpos femininos, à homogeneização dos comportamentos neurotípicos em mulheres, entre outras questões e considerando o corpo lésbico, isso significa que de algum modo essa literatura produzida serve para alargar essas estruturas normativas, para rompê-las, para escová-las a contrapelo.

O que quero dizer é que há muitas mulheres lésbicas de identidades complexas escrevendo sobre toda sorte de assuntos e que as abordagens que escolhem para dotar seus narradores, suas narradoras e protagonistas, bem como para construir sua lírica, passam, sim, por suas construções como indivíduos e como seres sociais. E se pensarmos que indivíduos dotados de sexualidades desviantes, ex-cêntricas, têm desejos desviantes e que esses desejos se realizam no mundo, na ocupação dos espaços desse mundo; e se essas mulheres integrais, dotadas de sexualidades desviantes criam novos significados para esses espaços; e se criam até mesmo novos espaços e novas geografias; e se criam novas metáforas de existência, por que não criariam por acaso uma produção literária outra? Trago a seguir alguns exemplos que podem somar-se a esse panorama.

Tomo por exemplo Marília Floor Kosby e seu livro, Mugido, que traz em seu cerne a mais xucra poética, termo mormente masculinista que remete ao campo, espaço de domínio no imaginário do homem e que a autora reivindica. A poeta revira a vaca para que vejamos suas entranhas, para que estranhemos nossos olhos-espelhos diante de um animal tão similar a nós mesmas. Algumas imagens produzidas são da vaca durante o parto, da vaca carneada, da vaca mocha, machorra, que é a vaca inútil, pois não produz leite nem reproduz prole, da vaca que carrega no lombo $700 \mathrm{~kg}$ de macho, da vaca das tetas esfoladas, e um útero imenso que arrebenta em violências no parto. Quantas mulheres? Marília ainda traz ao debate todo o entorno dessas imagens, a vida das mulheres do campo, a violência contida na escolha de uma alimentação carnívora: “e o coração de uma vaca sem nome / será que se come? / a ciência de se comer uma vaca / um quilo e tanto dentro do peito / cinco reais e treze centavos / por quatrocentos gramas / no balcão do supermercado" (Kosby, 2017, p. 39). Tomo por exemplo Nina Ferreira e sua Pérola marrom, exposta no mundo, nas grandes e pequenas cidades, das grandes pequenas certezas e dos grandes medos e constrangimentos:

não que eu quisesse ser outro ou / outra / mas eu li / sobre o que fizeram coa Luana, / sapatão como eu, mais escura que eu / e pensei: não quero / sair de casa hoje. / e feito minha mente fosse / máquina fotográfica, câmera full hd / me lembrei / do medo que eu sinto às onze no centro...meu constrangimento implantado / feito chip que botam nos pássaros / com certeza eles sabem / do pavor de que um cara armado, / honrado, / fardado / me veja como uma ofensa (Ferreira, 2018, p. 16).

Tomo por exemplo Angélica Freitas, que versificou as mulheres e seus úteros do tamanho de um punho, onde cabem rebeldia, regulações e igrejas. Angélica ainda evoca a presença de outras lésbicas - Bishop e Lota e Gertrude Stein -, traçando suas referências. Tomo como exemplo Luciany Aparecida e seu Auto-retrato, de Ruth Ducaso e Antonio Peixôtro, um tratado sobre o corpo e a destruição do gênero na base da escolha estética de autoria do livro. Com seu corpo todo desmembrado e fotografado por tios e tias, seu corpo que no fim é um autorretrato cindido, que quer quebrar todas as intrigas geográficas e ser amada por uma mulher renascida de desaguada em pintura clássica. Aproximo-me de Ruth Ducaso, assinatura estética de Luciany Aparecida, em seus Contos ordinários de melancolia, leio suas palavras de amor e liberdade, leio suas palavras que parecem ter sido articuladas por uma língua desconhecida e 
me perguntam sempre "mas se pode escrever assim?, então, se pode escrever tão potentemente, tão honestamente?" São textos que fazem ruir a lógica dos afetos protocolares e das submissões, textos que fazem ruir mesmo a lógica da linguagem e, por evocarem imagens tão controversas, que por vezes se aproximam do grotesco, do abjeto, a partir de narradoras que enjeitam a submissão, criam um espaço estético singular. "O que matei não foi só tu, minha irmã. Foi minha mãe. Eu sou o lobo-mal-da-chapeuzinho-vermelho, o que eu queria era comer todas as mulheres para tear a vida. Agora que aprendi a comer minha mãe, sou escritora" (Aparecida, 2018, p. 77). Tomo por exemplo Lisa Alves e sua escrita épica, de heroínas e mares que se abrem dentro e dentro mais. Tomo por exemplo Simone Teodoro (2016, p. 34), com um poema onde o grelo destrona o falo, porque é "lindo, é rijo, é talo". Tomo por exemplo Simone Brantes, que apreende o som do sexo entre mulheres, que apreende e reconfigura os marulhos das moças, seus desejos que produzem mar. Tomo por exemplo Mariam Pessah, que ao rasurar o próprio nome cria passagens marítimas e institui a revolução num grito autoproclamatório. Tomo por exemplo Cidinha da Silva, que, com sua escrita diligente, presente, fértil, inscreve as importâncias dos amores contemporâneos e ancestrais, inscreve a crítica ao genocídio das populações negras, inscreve a crítica de vidas negras e suas importâncias, inscreve outras cosmologias e orixalidades para outras identificações em literatura e, finalmente, que também fala de amor e das coisas simples e banalíssimas:

Amar é... passar a ferro o vestido da amada, quando não se gosta de passar, só para aliviar a pressa dela, que também não gosta de fzê-lo e está atrasada para o trabalho.

Amar é... compreender que o sangue da mulher amada tem cinco componentes: hemácias, plaquetas, leucócitos, polvilho e queijo. E sair pela cidade pouco conhecida, durante a chuva, à cata de um pão de queijo decente, quentinho, que lhe aplaque a crise de abstinência (Silva, 2018, p. 32).

Tomo por exemplo Tatiana Nascimento, que imagina futuros, imagina cuirlombos, imagina amores de terra e águas e cantigas tão no presente. Do amor e da sensualidade dos corpos amantes, dos corpos que gozam, que se têm. Tatiana é muito presente no Instagram, outra faceta muito bem aproveitada da contemporaneidade, de modo que ela também usa a rede para provocações e proposições teóricas urgentes, propõe lugares de discussão e de desconforto, lugares de pensar a nós mesmas e lugares de propor a leituras interseccionais, inclusive dos sujeitos que são lidos como sujeitos hegemônicos. Em sua força teórica e lírica, a autora imagina mundos sem deixar de problematizar o longo caminho a se percorrer. Tomo por exemplo Sarah Valle, numa viagem ao oriente, uma mulher em busca de si e, ao fim da viagem, não é um homem ou uma mulher que a salva. Não é nessa direção que a prosa vai, o que por si só já se destaca. E nas rasuras do desenho, tomo como exemplo Aline Zouvi, que trata de suas ansiedades e de suas relações com o mundo e com outros e outras artistas e suas condições de relacionar-se com o mundo. Como são importantes essas percepções, assim como Diana Salu, que além de seu Cartas para ninguém, uma novela gráfica poética, autobiográfica, realmente, cartas para ninguém e para todes que desejam saber, propõe-se a uma militância teóricoliterária no Instagram.

E se sairmos um pouco do Brasil? Na França, tomo o exemplo de Virginie Despentes e seu estrondo sexual, sua afronta ao patriarcado, suas polêmicas declarações que desestabilizam o cerne do movimento, porque talvez sejam eurocentradas demais, pertencentes a uma realidade outra - a que muitas não têm nem podem ter acesso - e, além disso, inconscientes demais de seus privilégios. Por isso, o tensionar os espaços é uma necessidade. Saber de onde a produção dessas lesbianidades sai e que espaços metafóricos produzem é trabalhar para que vozes plurais emerjam de onde não se esperaria, quebrando contratos. Na Colômbia, tomo como exemplo Andrea Salgado, lésbica futurista, com suas sexualidades migrantes e corpos que desafiam o desejo para pensar como será o futuro do sexo e dos sexos. Da Jamaica, residente nos Estados Unidos, tomo Nicole Denis-Benn que propõe um exercício de deslocamento, atirando-nos às complexidades do desejo e do afeto, da necessidade e da opressão, do colonialismo que transpiramos.

E se revisitarmos o passado, tomo como exemplo Violette Leduc, com sua Bastarda e Terese e Isabel, uma prosa que chocou sua época porque escolheu assuntos impróprios para mulheres. 
Tomo por exemplo Virginia Woolf, que teorizou sobre a escrita de mulheres no início do século, que pensou, criou e escreveu Orlando, inspirado em e dedicado a sua amante. Tomo por exemplo Tove Marika Jansson, com seus livros infantis, seus personagens fora dos padrões, os quais todas as crianças escandinavas conhecem. Tomo por exemplo Chiu Miao-Chin, vivendo a Taiwan e a Paris dos anos 1930, a expatriada que não foi salva, a expatriada que ficou tão deprimida a ponto de cometer suicídio. Tomo por exemplo Pat Parker e Audre Lorde, numa troca de correspondência que cria um documento histórico para o movimento lésbico, para o movimento negro.

Aqui me detenho para dizer que não quero apenas citar nomes, preciso contextualizar um pouco, de onde esses exemplos surgiram.

A captura de tela a seguir é um mapa intitulado Geografias Lésbicas em Literatura. É uma figura ampla de algo que se propõe interativo e, portanto, não se pode ver em detalhes, mas já há mais de 200 autoras efetivamente mapeadas (são 350 listadas). ${ }^{1}$ Cada ponto no mapa se abre em uma minibiografia, três obras e dois links sobre a autora (que não a Wikipédia). O epicentro está marcado na Ilha de Lesbos com a aba de Sappho.

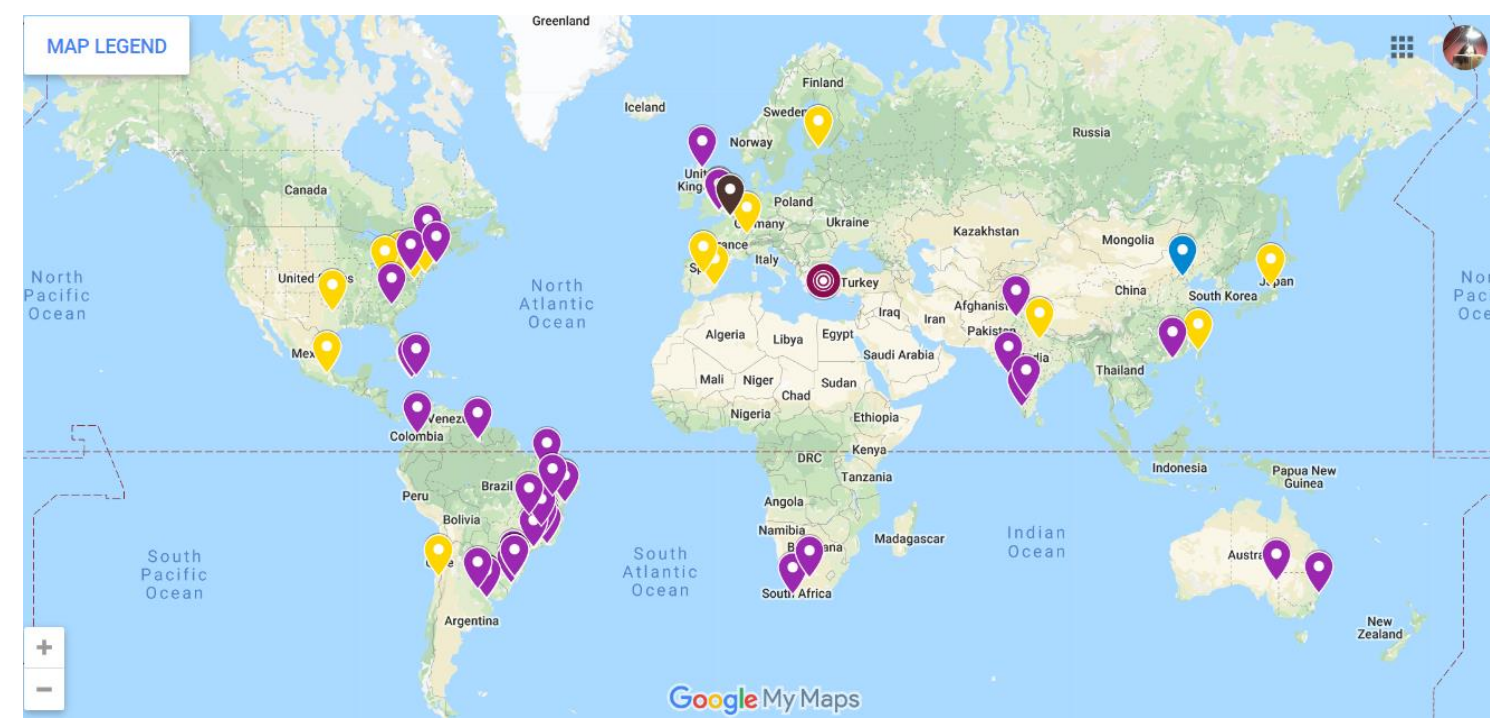

Figura 1 - Mapa Geografias Lésbicas em Literatura.

Elaboração própria.

Para o mapa, o termo lésbica (ou lésbica) está como elemento aglutinador de um grupo, no entanto, não prevê nem planeja homogeneizações, prevê observar as lesbianidades em literatura via geografia literária, de modo que é uma visão mundial, mas que só se completa na coletividade e na continuidade do trabalho. Os nomes que aventei anteriormente são apenas alguns exemplos, alguns excertos exemplares, apenas para corroborar o ponto que tento construir. Dessa pesquisa, desse mapeamento amplo e geral, vão surgindo alguns dados que me interessam como desdobramentos e que poderão interessar outres pesquisadores. Outros desdobramentos em que estou atualmente trabalhando são, por exemplo, um mapa de autoras contemporâneas brasileiras e um mapa sobre suas distribuições, isto é, um mapeamento de editoras (que delimito, a partir dos anos $2000 \mathrm{com} o$ marco da reedição de algumas obras de Cassandra Rios.).

Tenho lido com muito afinco autoras, críticas e teóricas lésbicas, brancas, não brancas, negras, indígenas, latino-americanas, europeias e não europeias, asiáticas, canônicas e não canônicas e, nessas leituras, tenho encontrado temas e desenvolvimentos bastante plurais. $\mathrm{O}$ estar no mundo dessas escritas se entranha nos espaços, produzindo modos novos de observação e de criação,

\footnotetext{
${ }^{1}$ Em outubro de 2020, quando da revisão deste artigo, o número de escritoras listadas era 543, sendo 252 brasileiras e 291 estrangeiras.
} 
ainda que em alguns espaços sejam apenas brechas, produzindo mesmo novas estéticas, novas éticas. Portanto, como pesquisadora, sinto-me no dever de promover também novas leituras, novas escutas. Evidentemente, nem sempre o texto apresenta as qualidades literárias que se espera, especialmente em se tratando de literatura. Contudo, quando há política e estética, quando se unem nesse exercício literário, o encontro é muito potente. É energia de transformação. A questão deste ensaio não é analisar a produção, como já mencionado, que é imensa, a questão é mostrar um pouco do que se fala quando se fala de literatura lésbica, uma pitada. É dizer que isso é muito maior do que a sexualidade isolada, é algo político e ético. Isso é inscrever, criar, reivindicar novos espaços estéticos, críticos, de procura, de existências. Isso é renovar o repertório tão desgastado de metáforas, isso é deslocar a crítica, muitas vezes preguiçosa, para um lugar de desconforto, um lugar que obriga a outros olhares. Sobretudo, essas geografias dizem respeito à possibilidade de encontrar, ressignificar, reivindicar, criar e recriar espaços onde o trânsito das mulheres lésbicas, cis ou trans, bissexuais e/ou mulheres queer seja possível. O estudo dessas geografias fornece uma crítica importante das interseções do patriarcado, dos sexos, da homofobia e do heterossexismo, entre outros, bem como a garantia de que lésbicas e suas espacialidades tornem-se visíveis, discutíveis e criticáveis. É pensar, a partir da literatura, as experiências espaciais de mulheres lésbicas e as limitações epistemológicas do campo teórico e crítico, além de contestar as narrativas hegemônicas, no campo político, que dizem respeito a vivências LBTQIAP.

No mais, o mapeamento de escritoras LBTQIAP atualmente traz 350 escritoras mapeadas mundialmente (até dezembro de 2019): 178 brasileiras no total, ${ }^{2}$ das quais 174 são brasileiras vivas, escrevendo atualmente, com livros próprios ou participação em coletâneas; 172 escritoras estrangeiras, entre essas, 106 escritoras estrangeiras vivas, escrevendo agora; e 66 escritoras estrangeiras que considero resgate histórico (reafirmação ou reinscrição na historiografia como LBTQIAP). O mapeamento começou a tender espontaneamente para escritoras LBTQIAP brasileiras contemporâneas e creio que a explicação mais plausível para isso seja a rede que se criou em torno do meu livro Amora (2015) e as demandas acadêmicas e culturais que surgiram a partir de seu reconhecimento no campo literário, bem como o surgimento da Padê Editorial, que, entre julho de 2018 e julho de 2019, se propôs a publicar artesanalmente os títulos de autoras LBT, em sua maior parte negras. ${ }^{3}$

Pensando em toda a produção com a qual tenho me deparado, não posso deixar de pensar que, se não somos também nossos corpos, como explicar tantos descaminhos? Se não somos também construções físicas, fisiológicas, metafísicas e espacializadas, como compreender tanta diversidade e, ao mesmo tempo, tanta prosa e lírica fora de uma curva padrão? Se pudéssemos atravessar o mundo só com a força do pensamento, se pudéssemos ser só discursos, não haveria dor. A dor é no corpo, na regulação da expressão do corpo, no comportamento do corpo, no desvio do corpo, em sua marcha resiliente, constantemente interrompida. Assim como o prazer também é no corpo, constantemente interrompido, mas quando consumado, potência de ser.

Então, quando digo lésbica (ou lésbica), sei da sua carga semântica e histórica, mas também acredito na fluidez da linguagem em seu próprio rio-processo. Palavra é ação. Se o gênero é performance e o discurso pode ser performativo, a performance é discursiva e se materializa no conjunto das atividades de comunicação. Fala, gesto, modos de vestir, de amar, de ocupar espaços, de escrever e ocupar espaços, criando novas metáforas. Reclamar a existência de uma literatura lésbica (ou lésbica) é, portanto, olhar com atenção as nuances dissidentes de sua produção tão plural. Reclamar uma literatura lésbica (ou lésbica) é escrevê-la e preocupar-se com sua escritura, ou seja, produzir textos que pensem essa produção em suas complexidades.

\footnotetext{
${ }^{2}$ Não tenho o número de lésbicas, bis, trans e queer separadamente, mas isso não é o foco do mapeamento, ainda que depois, evidentemente, quando o trabalho for geocrítico, isso aparecerá.

3 De acordo com o site da Padê Editorial "o \#ProjetoEscrevivências é um bonde de publicações de autoria LGBTQI, majoritariamente negras (75\% dxs autorxs se autodeclaram negrxs), que a publicou, de julho de 2018 a julho de 2019 , com apoio do Fundo Elas de Investimento social pela Cole-sã Escrevivências, homenagem ao conceito de Conceição Evaristo. A cole-sã tem organização e curadoria de Tatiana Nascimento, idealizadora e criadora do portal www.literatura.lgbt. Os títulos foram selecionados entre mais de 330 inscrições de todo o Brasil. Até junho de 2019, 45 títulos escritos por 57 autorxs foram publicados."
} 
Mas o que significa afinal a construção de lesbianidades plurais? Tenho pra mim, que isso significa resistir a uma ordem arbitrária do desejo, dos modos estabelecidos de ocupação dos espaços, e da produção de narrativas que se encaixam no discurso hegemônico, classista, capitalista, racista, capacitista, antifeminista. É fazer a leitura das intersecções do sujeito interpretado como hegemônico. E, sobretudo, para não se frustrar, estar ciente de que nem toda a literatura lésbica (ou lésbica) será excelente e revolucionária, pois não será.

De toda forma, justamente porque há o desejo de tocar a pluralidade identitária ocupada pelas diferentes performances da sexualidade, não posso me eximir de dizer que há lésbicas brancas classistas, burguesas, racistas e que desejam operar de acordo com os padrões sociais estabelecidos. E, por isso, talvez não criem nem proponham narrativas ou líricas extraordinárias. Apesar de não me interessarem como objeto, essas leituras também são necessárias. A desconstrução e a descolonização dos corpos e das sexualidades é um processo, um exercício de questionamentos, diálogos, escutas e práticas constantes. Não é uma chave que de repente vira. E como não podemos cair em universalismos, há que se contar com alguma resistência interior no movimento também, no modo de ocupação dos espaços. Uma pressão interna, que dá mais intensidade ao debate e só colabora para pensar distintas construções de sexualidades, além de pensar o espaço como fator indispensável. Por exemplo, algumas escritoras e artistas, apesar de se identificarem como lésbicas ou identificarem seu desejo direcionado a outra mulher, não pensam que sua escrita seja lésbica, tampouco contra-hegemônica. Sempre pergunto se a autora quer ser incluída no mapa. Há que se respeitar a autodeclaração. É igualmente pensando nessas escritoras que escrevo este ensaio. Muitas perguntas ficaram rondando minhas certezas, roendo alguns pilares, descamando palafitas, balançando o solo frágil sob meus pés.

Alguns fatores compõem essa conta. Por exemplo, há pessoas que não se conformam com as nomenclaturas que hoje dão conta das nossas sexualidades e, portanto, pensam seus desejos de um modo mais fluido. É como ter que pensar em mulheres lésbicas que não se identificam com a categoria "mulheres" ou que são mulheres queer ou que são pessoas não binárias, ou assexuadas ou mesmo sapatonas. Outras pessoas pensam suas identidades de modos mais não normativos e suas performances nos obrigam a criar códigos linguísticos mais abrangentes e mais inclusivos. Essas podem compreender este estudo como algo datado. Eu entendo que, daqui a alguns anos, talvez esse texto não seja necessário, talvez não seja nem compreendido, num mundo ideal de corpos livres. Todavia, por ora, o estudo tem uma função política para pensar estéticas e epistemologias. Há também quem não esteja interessada em questões de ordem político-social e que acredita que a literatura deve transitar longe desses parâmetros ditos identitários. Há quem pense que esses fatores não devem ser levados em conta quando se avalia literatura. Para mim, isso é uma espécie de crença ingênua na estética como categoria pura, que deixa de pensar todas as nuances da contemporaneidade. Ou seja, o que muda fundamentalmente é o modo de compreender as esferas da episteme, o modo de estar no mundo e de tentar dar conta das práticas. O mesmo problema surge num outro extremo da análise.

O fato é que, em alguma instância, pensando nos diversos atravessamentos do ser social, todas essas, do ponto de vista do afeto, continuam sendo construções de lesbianidades, continuam não totalmente conformes com o desejado, o esperado e/ou o normativo e continuam criando novas estéticas, novos afetos, novos modos de ocupar os espaços e, portanto, de criar narrativas, lembrando que relacionamos esse estar no mundo com a ideia de contínuo lésbico de Rich (1986). Nossas complexas relações eróticas foram sequestradas, tolhidas e transformadas em algo que não nos pertenceria mais. Além disso, assim como mulher não é um signo uno, feminismos precisam ser plurais e lesbianidades também. Por isso, o conceito de interseccionalidade é uma palavra que deve sempre cruzar nosso campo semântico.

Assim, lembro-me de quando conheci o discurso de Sojourner Truth: "Não sou eu uma mulher?", de 1851, e pensei que este antecedia em quase cem anos a reflexão de Primo Levi, em "Se isto é um homem?", sobre a condição humana, sobre as formas de opressão e extermínio e, no caso de Sojourner Truth, sobre mulheres negras (Brah; Phoenix, 2004). Afinal, a que construção de humanidade se referem as narrativas? Que perspectivas mulheres LBTQIAP abrem em suas insubordinadas escrituras? O discurso de Sojourner começa dizendo que onde há muito barulho 
deve haver algo fora de ordem. E há algo estrondoso na pergunta Não sou eu uma mulher? O deslocamento que promove ao pedir que examinemos nossos lugares e que, dali, olhemos de verdade para os outros é fundamental para os entendimentos aqui propostos. Nesse sentido,

a homogeneidade das mulheres como um grupo é produzida não com base na essência biológica, mas numa universalidade sociológica e antropológica secundária. Dessa maneira, por exemplo, em qualquer momento da análise feminista, as mulheres são caracterizadas como um grupo específico cujo denominador comum é a opressão compartilhada (Mohanty, 2017, p. 317).

Opressões compartilhadas, diria, no plural, e suposta universalidade sociológica, que é o que precisamos compreender, pois sabemos que as opressões nos interpelam de modos diferentes no mundo, nos espaços do mundo. Não se pode dizer que juízos são isentos ou universais, tampouco usar do jugo da opinião para apagar, menosprezar, deslegitimar narrativas para as quais nunca olhamos de verdade. Aliás, como vamos fazer isso, sem assumir que estamos inundados pela ideologia da heterossexualidade, da branquitude, do ocidente, do sistemamundo pautado em fatores econômicos?

Por isso insisto que pensar literatura lésbica via uma geografia literária que propõe leituras da ocupação dos espaços por corpos interpretados como interseccionais retira a ideia homogeneizante de que há signos unos. Há mulheres, meninas, lésbicas, machorras, machudas, machonas, sáficas, cássias ellers, sapatonas, sapa, brejeiras, cola-velcro, mulher-gay, marimachos, fanchas, viadas, rachas, rachas-macho, caminhoneiras, dykes, butches, discretas, melissas, fanchonas, sapatilhas, lambe-xanas, que são brancas, negras, não brancas, indígenas, pobres, ricas, hegemônicas, não hegemônicas etc.

Uma vez um jornalista me perguntou se acaso eu escrevia com minhas genitais. Ele também se apressou em responder e concluir que se não escrevíamos com nossas genitais, não poderia existir uma literatura lésbica, tampouco hétero. Não? Eu escrevo com meu corpo inteiro. Escrevo com ele, escrevo com seus gestos e ações. Escrevo com as sensações que o acometem e seus impulsos nervosos também. Escrevo com as opressões que o interceptam. Escrevo com os prazeres. Minhas mãos são lésbicas, minha cabeça é de mulher lésbica, meus olhos, quando olham pela janela, são olhos de uma mulher lésbica, meus pés, quando percorrem espaços, levam um corpo lésbico, respondi, não solicitada. As lésbicas não estão submetidas ao desejo erótico do masculino. As lésbicas podem ser livres e não apontam seu desejo ao masculino. As lésbicas não se conformam com o falo. Para as lésbicas, a premissa falocêntrica é ignorada no que tange ao desejo. E o falo, em vez de masturbado, é perturbado. A perturbação do falo nunca causa preocupação às lésbicas, em última instância, causa riso. Esse riso rebelde é parte.

Lésbicas são compostas de rebeldia.

É com esta rebeldia que escrevo. É ela que se entranha no meu gesto. É a rebeldia que esfrega minha caneta numa folha branca, é a rebeldia que faz meus dedos oscilarem no teclado, é a rebeldia que faz minha língua procurar a palavra úmida, a palavra túmida, a palavra viva, a palavra rósea, a palavra minha, a palavra rompida e amorosa.

É com esta ruptura que escrevo. É ela que me afasta, que me brecha, que me frincha, que me fenda, que me racha, que me rasga, que me greta, é por essa ruptura que sou grata.

É com essa gratidão que escrevo.

Não pensar a identidade em camadas, mas como uma liga. Não quero dizer amálgama, porque, apesar do som amolecido, é uma liga metálica. Quero pensar numa fluidez maior das ações do desejo, mas quero também ser política.

É com política que escrevo. É ela que me pulveriza e galvaniza, ela que me põe em relação, que me estabelece e desestabiliza.

Contudo, não somos abstrações discursivas, tampouco somos a distinção cartesiana. Não somos o binarismo fundamental corpo-mente. Não somos apenas como nos pensamos senão a materialidade desse fenômeno. Sou corpo pensante no mundo. Sou mulher. Sou lésbica. Sou escritora lésbica no mundo. No mundo sou com todes e, por vezes, ocupamos o mesmo espaço, mesmo contra as leis da física, porém ocupamo-lo de mil formas diferentes e compartilhadas. 
Atravessa-me o corpo a discussão sobre a pluralidade dos signos, sobre a rebeldia nele contida, sobre a fresta, a frincha, a graça, la joie, la jouissance, por ser experiência, aí digo, da mulher, dessas multiplicidades. A ideia propagada de um feminino único e essencial, com o qual, em algum ponto da vida, sentimos a necessidade ou a obrigatoriedade de estar em contato, para mim é falsa. A ideia desse feminino vinculado ao sagrado se configura numa espécie de busca ontológica, antropológica e mesmo cosmogônica de uma subjetividade anterior, talvez, uma subjetividade mais conectada à natureza ou anticolonial, em que a função da linguagem é estabelecida como encantamento, como magia ou como anticolonialidade dos corpos. Mas quem disse que isso é algo que deve ser atribuído apenas às mulheres? Isso era a base de uma sociedade pré-capitalista. Essa divisão natureza e cultura, sentimento e razão, é uma divisão criada em oposições simplistas. Embora existam trabalhos fundamentais muito interessantes, esses homens que pensaram arduamente para tentar entender a sexualidade humana (Freud, Lacan, Levi-Strauss, Foucault etc.) partiram de um ponto em que a heterossexualidade era dada. E de onde a mulher já começava com uma falta, uma deficiência, uma desvantagem em relação à sua integridade de sujeito.

Ocorre-me pensar que, em seu sentido pleno, as lésbicas gozam mais. Do ponto de vista dessas teorias, as lésbicas são mulheres que deram errado. Desvios da norma. Mas se olharmos um pouco mais à margem dessas teorias, encontraremos Monique Wittig, Adrienne Rich, Judith Butler, bell hooks, Angela Davis, Gayle Rubin, Paul B. Preciado, M-H Sam Bourcier, Gloria Anzaldúa, Yuderkys Espinosa, Chandra Talpade Mohanty, Luce Irigaray, Tania Navarro, Maria Lugones, Lelia Gonzales e tantas outras mulheres, lésbicas ou não, para apontar o problema dessas construções às quais damos tanto crédito e sobre as quais ousamos estabelecer as tíbias palafitas da nossa sociedade (e agora nos debatemos em conceitos gastos, agora assistimos análises estapafúrdias). Se o desejo lésbico transcende as categorias do sexo, se ser lésbica contesta esse edifício chamado sexo, se deixa de reatualizar o mito da feminilidade, se quebra os contratos com a heteronormatividade, se busca novas formas de masculinidades, se rompe com a inveja do falo, se confunde essa ficção reguladora do gênero, se questiona a universalidade da opressão, se não conforma com a economia fálica, flácida e masculinista das estruturas de parentesco, então, a lésbica desestabiliza todas essas premissas sobre as quais fundamos a sexualidade e a civilização. Portanto, gozam, sim, mais plenamente.

E se a noção de sujeito que herdamos do ocidente foi fundada na língua, na autorreferência do sujeito na linguagem, não posso deixar que essa mesma linguagem me domine, negando a minha existência. Nem que me impeça de discutir a minha posição política e teórica no mundo com a minha própria língua. É preciso efervescer, transbordar outros significados. Não quero palavras esturricadas pelo sol e pelo sal da teoria, da crítica, do pensamento ocidental, colonizado. Não quero palavras recalcadas pela opressão, palavras murchas, palavras-falta. Quero palavras gordas, larvas espumosas aquosas que estourem sobre nossas línguas como supernovas deixando durar seus gostos extravagantes e inexplicáveis. Quero a palavra lésbica abrindo minha boca com línguas, sibilos, oclusões sorridentes, fricativas ruidosas, abertas e plurais. Mas quero também rasurá-la, para que isso me lembre de que essa palavra tem uma construção histórica e espacial. Quero essa prosa e essa poesia.

Que gosto tem a palavra lésbica na boca de cada uma? Que gosto tem uma escrita lésbica? De que terra brotam? Que coisas sumarentas produzem? Que espaços inventam com suas secreções? Que segredos secretam? Que gozo gozam? Gozam sem a ideia de incompletude? Ou sem a ideia máscula de preencher uma falta?

Se olhar para o lado e agora um espelho acomodar sua face, será a face de uma lésbica ou de uma lésbica. Será uma alteridade refletida num falseio. E é só dessa maneira que posso compreender que sou uma pessoa incompleta, quando me vejo outra. Minha completude é sempre adiada no momento em que me encontro outra. Ela só é completude no encontro com alguém. Não é o mesmo preenchimento de uma falta simbólica, feito pelo dominador que possui o elemento faltante. Se olho no espelho, o entorno que esta figura ocupa é o de uma moldura que cerceia o espaço. Essa falta não pode ser tão simplória. Nossas múltiplas incompletudes apenas serão vistas e compreendidas justamente no entendimento de sua 
multiplicidade. Não como um elemento que pode ser encontrado através do desejo de poder, mas com o reconhecimento das nossas diferenças e a proposição de ações.

Que espaços ocupam as lésbicas? Que espaços podem ocupar sem que sejam impedidas de viver sexual e politicamente plenas? ${ }^{4}$ Como o questionamento às práticas sociais está incluído nessas estruturas que se sufocam na primazia da linguagem?

É na contestação dessas estruturas identitárias que reside nosso estar no mundo. E aqui, uso a palavra lésbica de forma farta, tentando englobar discursos e práticas de sexualidades desviantes produzidos por mulheres. As identidades se apresentam no corpo, num conjunto de práticas que o corpo exerce, num espaço que o corpo ocupa, sempre em relação à. Desse modo, são nossas labirínticas faltas plurais, e não a falta de algo inventado, que nos fazem sujeitos e sujeitos políticos. E é essa compreensão que me alerta para caminhos alternativos mais do que para estruturas fixas e normas. Se não nos faltassem elementos, estaríamos conformadas.

As questões evocadas ao pensarmos em literaturas lésbicas (ou lésbicas) não são questões banais, porque se ligam imediatamente com estruturas de opressões danosas a todas as mulheres em menor ou maior grau. Pensar em sua produção, sua viabilização, sua distribuição, sua recepção em livrarias e junto ao público leitor, na academia, na crítica, é uma reflexão necessária e urgente. E, principalmente, são ações, escolhas, práticas e discursos no mundo. Se quisermos modificar alguma coisa no campo literário, que é regido por relações de poder, que são relações de opressão e de hierarquia de gênero, raça e classe, relações capitalistas de exploração e de lucro, precisamos nos colocar numa posição que desestabiliza essas relações pré-estabelecidas. Se ser lésbica pode significar ser rebelde, romper com um contrato, a importância desse ato político se amplia no campo, cria uma frincha. É nela que enfiaremos nossas línguas, é nela que depositaremos nossas palavras.

Não é só na geografia que este ensaio quer operar, ele quer, por meio da geografia, por meio de um pensamento espacializado, operar na episteme. Ressignificar não pode nunca ser ato banal. Para ressignificar é preciso percorrer caminhos, recolher bagagens, problematizar trajetos, olhar atentamente para onde estamos indo, e de onde viemos.

Não vivemos nossas questões num espaço-tempo abstrato, teórico, absoluto. Nós vivemos nossas questões num mundo pautado por diversos saberes, ignorâncias, poderes e carências. É preciso sujar as mãos para criar novos espaços a ocupar, revolver a terra, assentar pedras, vigiar algum capim. É preciso viver a geografia e tropeçá-la. É preciso encontrar modos desobedientes de pensar de novo e de novo. Talvez essas notas tenham me dado pouco sobre o que é ser uma mulher, ou o que é ser uma lésbica. De toda forma, algo ficou mais nítido, lésbicas e mulheres não são do modo que nos foram entregues discursivamente. Não posso dispensar um histórico de construção e desconstrução que envolve tanta aprendizagem e transformação de sentimentos, de pensamentos. Não posso aceitar conceitos desgastados. Posso sim, na mesma moeda, fortalecer o que minha experiência faz deles todos os dias.

A prosa e a poesia não reproduzem o real tal e qual, nem poderiam fazê-lo, não acredito em uma função simples, mas acredito que ela atualiza o potencial dos referentes de realidade, o potencial da realidade expresso ou ainda não expresso. A literatura projeta horizontes.

\section{Referências}

ANZALDÚA, Gloria (2017). Queer(izar) a escritora: loca, escritora y chicana. In: BRANDÃO, Izabel et al. (Org.). Traduções da cultura: perspectivas críticas feministas (1970-2000). Florianópolis: Edufal; Editora da UFSC.

APARECIDA, Luciany (2017). Contos ordinários de melancolia. Salvador: Boto-cor-de-rosa livros; ParaLeLo13S.

APARECIDA, Luciany. Auto-retrato. Salvador: Pantim, 2018.

\footnotetext{
${ }^{4}$ Por que os assassinos de Marielle Franco não foram responsabilizados? Quem não a quis conquistando espaços significativos, espaços políticos, espaços capazes de reivindicar outros campos de plenitude?
} 
ARNÉS, Laura (2016). Ficciones lesbianas: literatura y afectos em la cultura argentina. Buenos Aires: Madreselva.

BRAH, Avtar; PHOENIX, Ann (2004). Ain't I a woman? Revisiting intersectionality. Journal of International Women's Studies, v. 5, n. 3, 2004, p. 75-86. Disponível em: http://vc.bridgew.edu/jiws/vol5/iss3/8. Acesso em: 28 jan. 2020.

BRANDÃO, Izabel et al. (Org.) (2017). Apresentação. In: BRANDÃO, Izabel et al. (Org.). Traduções da cultura: perspectivas críticas feministas (1970-2000). Florianópolis: Edufal; Editora da UFSC.

BROWNE, Kath; FERREIRA, Eduarda (2015). Lesbian geographies: gender, place and power. London; New York: Routledge.

BUTLER, Judith (2017). Problemas de gênero: feminismo e subversão da identidade. Rio de Janeiro: Civilização Brasileira.

BUTLER, Judith (2004). Undoing gender. New York: Routledge.

Collot, Michel (2011). Le pensée-paysage. Paris: Actes Sud.

COLLOT, Michel (2014). Pour une géographie littéraire. Paris: Éditions Corti.

FERREIRA, Nina (2018). Pérola marrom. Brasília, DF: Padê Editorial.

JAGOSE, Annemarie (2017). Queer. In: BRANDÃO, Izabel et al. (Org.). Traduções da cultura: perspectivas críticas feministas (1970-2000). Florianópolis: Edufal; Editora da UFSC.

KOSBY, Marília Floôr (2017). Mugido. Rio de Janeiro: Garupa.

MOHANTY, Chandra Talpade (2017). Sob o olhar ocidental. In: BRANDÃO, Izabel et al. (Org.). Traduções da cultura: perspectivas críticas feministas (1970-2000). Florianópolis: Edufal; Editora da UFSC.

POLESSO, Natalia Borges (2018). Geografias lésbicas: literatura e gênero. Revista Criação \& Crítica, n. 20, p. 3-19.

RICH, Adrienne (2012). Heterossexualidade compulsória e existência lésbica. Bagoas - Estudos gays: gêneros e sexualidades, v. 4, n. 5, p. 17-44. Disponível em: https://periodicos.ufrn.br/bagoas/article/view/2309.

SILVA, Cidinha da (2018). O homem azul do deserto. Rio de Janeiro: Malê.

TEODORO, Simone (2016). Movimento em falso. São Paulo: Patuá.

WITTIG, Monique. The straight mind and other essays. Boston: Beacon Press. 